\title{
The role of immunotherapy in eliminating high-risk treatments for pediatric cancer
}

\author{
Zahra Farhoud ${ }^{1, *}$, Sepehr Bozorgchenani² \\ ${ }^{1}$ Department of Veterinary Medicine, Rasht Branch, Islamic Azad University, Rasht, Iran \\ 2Department of Bioinformatics, Tehran Branch, University of Science and Culture, Tehran, Iran
}

\begin{abstract}
Chemotherapy, radiation, and surgery are often ineffective in treating refractory or chronic tumors in children. Recent advances in cancer immunotherapy have also improved the outcome of many human tumors, resulting in significant responses in patients who have previously refused to respond to other treatments. The immune system is made up of cells and proteins that work together to maintain immunity against pathogens. Cancer cells can adapt and metastasize over time, express different neoantigens, or express more immune-suppressing mechanisms, allowing them to be identified and eradicated. In this study, we focus on immunotherapy for pediatric cancer and its progression using natural killer (NK) cells, chimeric antigen receptor T cells (CAR-T), and oncolytic virus cells in these patients. For all intents and purposes, toxicity is a concern. Although immunotherapy is believed to have fewer long-term side effects than chemotherapy and radiation therapy, they may have a high rate of short-term side effects, depending on the cause and purpose. These complications can lead to lifethreatening illnesses, from mild illnesses such as fever and headaches to more severe illnesses such as autoimmune, neurotoxicity, and opportunistic infections. Any of the problems listed, for example, cytokine release syndrome, can be fatal. Different intensities require multiple tests and trials.
\end{abstract}

Keywords: Children cancer, Natural killer cells, CAR-T

\section{Introduction}

Chemotherapy, radiation, and surgery are often ineffective in treating resistant or chronic tumors in children. For many cancer patients, immunotherapies have been a promising treatment choice [1]. Despite advances in chemotherapy and radiotherapy that have increased average survival rates for children with cancer in recent decades, childhood cancer remains the leading risk factor for mortality under the age of 20 [2].

Recent advances in cancer immunotherapy have improved the outcome of several human cancers and in some cases led to promising responses in patients who were previously unable to respond to other types of care [3-6]. Immunotherapy has been used to treat cancer since the late 1800 . Wilhelm Bush observed tumor regression in 1866 after a rose infection in a patient with sarcoma. Shortly afterward, in 1891, streptococcus and its toxins were injected into the bloodstream by gypsies, and some patients with nonsurgical sarcoma recovered [7-10].

The immune system is a diverse and intertwined collection of cells and proteins that function together to kill pathogens while preserving resistance to autoimmunity [11]. Other functions of the immune system include focusing on immune monitoring and

\footnotetext{
* Corresponding author:

Zahra Farhoud, BSc

Department of Veterinary Medicine, Rasht Branch,

Islamic Azad University, Rasht, Iran

Tel/Fax: +98937 7811335

Email: z.farhoudkhomeirani@gmail.com

https://orcid.org/oooo-0oo1-6598-2832
}

(C) The Author(s) 2021

Received: May, 13, 2021

Accepted: May, 27, 2021 
penetration of immune cells and tumor cytolysis in cancer patients. Burnet and Thomas first described immunosurveillance in 1957, which occurs when a tumor is recognized as 'foreign' in the body [12, 13]. The evolution, metastasis, and expression of neoantigens, as well as the use of different pathways to inhibit the immune system, are all influential characteristics of cancer cells. As a result, they are resistant to identification and deletion. Thus, the safety version should focus on 3 steps, which include deletion, balance, and escape [14]. During the removal of cancer cells, immune and innate cells detect new antigens, followed by the formation of tumor-reacting $\mathrm{T}$ cells and the removal of the tumor. Any cancer cells that exist in the removal process make it to the equilibrium level. During the equilibrium time, the adaptive immune system keeps the tumor inactive. Finally, cancer cells evolve to avoid recognition by the immune system, resulting in an escape pathway marked by tumor growth and/or T-cell exhaustion [14, 15].

In this study, we intend to examine immunotherapy methods to reduce the adverse effects of previous traditional therapies, considering the differences between pediatric and adult cancers.

\section{The difference between cancer in children and adults}

In pediatric cancer, most embryonic cells are involved in the development of the disease, and thus the accumulation of genetic mutations and transcriptional abnormalities is thought to cause cancer in children [16]. Other research on the causes of childhood cancer has shown that children with Fanconi anemia are more likely to grow cancer at a median age of 16 years [17]. BRCA2 mutations have been identified in Fanconi anemia, along with 15 other potential mutations, resulting in congenital abnormalities, bone marrow dysfunction, and an elevated risk of developing myeloid and solid malignancies $[18,19]$.

\section{Chimeric antigen receptors $\mathbf{T}$ cells in} pediatric cancer

Immunotherapy with chimeric antigen receptors $\mathrm{T}$ cells (CAR-T), first recorded in the mid-1980s, increased hope for cancer care and ignited global interest in immuno-oncology [20]. The formation of CAR-T cells and natural killer (NK) cells resulted from combining the anti-cancer action of immune system cells such as T and NK cells with the idea of antibody specificity to redirect these cells' cytotoxic activity to target tumor cells expressing a specific antigen [21].

Tumors' ability to escape the immune system is due to the tumor's composition, which modulates the function of human leukocyte antigen (HLA) molecules or tumor antigens, as previously mentioned. CAR is an acceptable therapy choice since it is designed to contain a specific antigen without the need for HLA neoantigens of tumor genes to overcome the difficulties. A chimeric antigen receptor is composed of an extracellular domain with an antigen-binding domain derived from a monoclonal antibody specific for a tumor surface antigen, a spacer domain, a transmembrane domain, and an intracellular signaltransducing chain of the T-cell receptor $[22,23]$. A specific vector could be used to diagnose most patients with cancers that express the target antigen [24].

\section{Natural killer cells}

Human NK cells are formed from multipotent CD34+ hematopoietic progenitors in the bone marrow. NK cell maturation occurs in both the bone marrow and the lymphoid glands and, unlike $\mathrm{T}$ cells, does not include the thymus [25-27]. NK cells are intrinsic lymphocytes that can suppress cancer. Unlike $\mathrm{T}$ cells, NK cells are activated without any previous contact with cancer cells. The function of NK cells is determined by a combination of inhibitory activation signals by receptor-ligand interaction. Activating receptors such as NKp46, NKp44, NKp3o, DNAM1, and NKG2D identify tumor antigens and activate NK cells. These NK cells secrete cytotoxic granules containing perforin and granzymes, which directly kill cancer cells by inducing apoptosis through various mechanisms including the Fas and TRAIL pathways. NK cell stimulation in the tumor microenvironment can also play a role in dendritic cell and $\mathrm{T}$ cell recruitment to the tumor site. NK cells may also be activated by monoclonal antibodies that target CD16, such as daratumumab for multiple myeloma and TALL or rituximab for B cell non-Hodgkin lymphoma [28, 29]. Peripheral tissue, cord blood, and induced pluripotent stem cells (iPSC) from haploidentical, allogeneic, or autologous donors can all be used to separate NK cells [30]. NK cells play an important role in the transplantation of allogeneic and autologous hematopoietic stem cells. A few genes, including KIR, 
NKG2D, and their ligands, regulate cytotoxicity in leukemia. These cells can invade several leukemic cell types, including acute myeloid leukemia (AML), chronic myeloid leukemia (CML), and chronic lymphocytic leukemia (CLL), with little risk of acute graft against host disease [31-33].

\section{Pediatric brain tumor immunotherapy}

The immune system finds the central nervous system (CNS) to be a privileged location, in addition to complementing immune cells and signals that act on the rest of the body. The blood-brain barrier (BBB), a highly specialized bond between blood and the CNS parenchyma caused by capillary endothelium, nursing cells, and astrocytes, determines this safe score [34]. Pediatric brain tumors are made up of a variety of histologic subtypes that occur with varying degrees of aggressiveness in the central nervous system [35]. CNS tumors are the most prevalent solid tumors in children, as well as the high incidence of cancer-related mortality [35]. Although overall childhood cancer survival rates have risen significantly in recent decades, improvement in pediatric CNS tumors has lagged behind that of hematological cancers [36]. William Coley introduced bacteria into various tumors in the late 1800 s to stimulate an immune response, and hence the idea of stimulating the immune system to combat cancer (also known as rapid immunotherapy) was born [8]. Researchers have since discovered how the immune system communicates with tumor cells in the hopes of channeling these abilities to develop effective immunotherapies. Antigen presentation on major histocompatibility complex (MHC) molecules, as well as antigen presentation that is not MHC-dependent, are used to activate the immune system. By digesting intracellular and extracellular proteins into small peptides, extracellular display on class I or class II MHC molecules for MHC-dependent activation is accomplished [37].T cells use their T-cell receptor (TCR) to recognize peptides on the MHC molecule as antigens, eliciting an immune reaction [38]. Peptide binding to the MHC is strongly influenced by a patient's HLA genotype, which must be taken into account when developing and implementing antigenbased therapies. Antigen epitopes can also stimulate the immune system in non-MHC-dependent ways, such as antibody-dependent B-cell activation [39].

\section{The role of oncolytic viruses in cancer immunotherapy}

Another way to stimulate the immune system to fight tumors is to use oncolytic viruses, so viruses that are widely used in this field can be called herpes simplex virus, adenoviruses, measles virus, and poliovirus to attack and infect cells noted cancer. This specificity can be achieved by inserting tissue-specific promoters that ensure viral replication occurs only in target organs, or by removing specific genes that ensure viral replication occurs only in actively individual cells [40]. An oncolytic virus infection not only kills tumor cells directly but also stimulates PAMPs and DAMPs, resulting in immunogenic cell death and adaptive immune responses [41].

\section{Conclusion}

Given all of the benefits, toxicity is a cause for concern. Although immunotherapies are believed to have fewer long-term side effects than chemotherapy and radiation, they may have a high rate of short-term adverse effects that range in magnitude based on the agent and the target. This can vary from mild inconveniences such as fevers, headaches, and chills to more severe conditions such as myalgia, autoimmunity, neurotoxicity, and opportunistic infections; any of these incidents for example, cytokine release syndrome can be fatal. The immunosuppressive tumor microenvironment is also a recurring issue in solid cancers, since it may reduce or eliminate all immunotherapeutic gain [2]. As a result, various intensities necessitate several measurements and trials.

\section{Author contributions}

All authors are equally involved in the preparation of this manuscript and endorse the manuscript.

\section{Conflict of interests}

The authors declare that they have no conflicts of interest.

\section{Ethical declarations}

Not applicable.

\section{Financial support}

None to be declared. 


\section{References}

1. Wedekind MF, Denton NL, Chen CY, Cripe TP. Pediatric Cancer Immunotherapy: Opportunities and Challenges. Paediatr Drugs. 2018; 20(5):395-408.

2. Hutzen B, Paudel SN, Naeimi Kararoudi M, Cassady KA, Lee DA, Cripe TP. Immunotherapies for pediatric cancer: current landscape and future perspectives. Cancer Metastasis Rev. 2019; 38(4):573-94.

3. Wolchok JD, Chiarion-Sileni V, Gonzalez R, Rutkowski P, Grob JJ, Cowey CL, et al. Overall Survival with Combined Nivolumab and Ipilimumab in Advanced Melanoma. N Engl J Med. 2017; 377(14):1345-56.

4. Motzer RJ, Tannir NM, McDermott DF, Arén Frontera O, Melichar B, Choueiri TK, et al. Nivolumab plus Ipilimumab versus Sunitinib in Advanced Renal-Cell Carcinoma. N Engl J Med. 2018; 378(14):1277-90.

5. Maude SL, Laetsch TW, Buechner J, Rives S, Boyer M, Bittencourt $\mathrm{H}$, et al. Tisagenlecleucel in Children and Young Adults with B-Cell Lymphoblastic Leukemia. N Engl J Med. 2018; 378(5):439-48.

6. Mazraedoost S, Behbudi G. Nano materials-based devices by photodynamic therapy for treating cancer applications. AANBT. 2021; 2(3):9-21.

7. Coley WB. II. Contribution to the Knowledge of Sarcoma. Ann Surg. 1891; 14(3):199-220.

8. McCarthy EF. The toxins of William B. Coley and the treatment of bone and soft-tissue sarcomas. Iowa Orthop J. 2006; 26:154-8.

9. Coley WB. The treatment of malignant tumors by repeated inoculations of erysipelas. With a report of ten original cases. 1893. Clin Orthop Relat Res. 1991; (262):3-11.

10. Nauts HC, Fowler GA, Bogatko FH. A review of the influence of bacterial infection and of bacterial products (Coley's toxins) on malignant tumors in man; a critical analysis of 30 inoperable cases treated by Coley's mixed toxins, in which diagnosis was confirmed by microscopic examination selected for special study. Acta Med Scand Suppl. 1953; 276:1-103.

11. Uehara T, Fujiwara T, Takeda K, Kunisada T, Ozaki T, Udono H. Immunotherapy for Bone and Soft Tissue Sarcomas. Biomed Res Int. 2015; 2015:820813.

12. Burnet M. Cancer: a biological approach. III. Viruses associated with neoplastic conditions. IV. Practical applications. Br Med J. 1957; 1(5023):841-7.

13. Masoumzade R, Behbudi G, Mazraedoost S. A medical encyclopedia with new approach graphene quantum dots for antibreast cancer applications: mini review. AANBT. 2020; 1(4):8490.

14. Schreiber RD, Old LJ, Smyth MJ. Cancer Immunoediting: Integrating Immunity's Roles in Cancer Suppression and Promotion. Science. 2011; 331(6024):1565.

15. Peggs KS, Quezada SA, Allison JP. Cell intrinsic mechanisms of T-cell inhibition and application to cancer therapy. Immunol Rev. 2008; 224:141-65.

16. Marshall GM, Carter DR, Cheung BB, Liu T, Mateos MK, Meyerowitz JG, et al. The prenatal origins of cancer. Nat Rev Cancer. 2014; 14(4):277-89.

17. Alter BP. Cancer in Fanconi anemia, 1927-2001. Cancer. 2003; 97(2):425-40.

18. Kutler DI, Auerbach AD, Satagopan J, Giampietro PF, Batish SD, Huvos AG, et al. High incidence of head and neck squamous cell carcinoma in patients with Fanconi anemia. Arch Otolaryngol Head Neck Surg. 2003; 129(1):106-12.

19. Kutler DI, Singh B, Satagopan J, Batish SD, Berwick M, Giampietro PF, et al. A 20-year perspective on the International Fanconi Anemia Registry (IFAR). Blood. 2003; 101(4):1249-56. 20. Gross G, Waks T, Eshhar Z. Expression of immunoglobulin-Tcell receptor chimeric molecules as functional receptors with antibody-type specificity. Proc Natl Acad Sci U S A. 1989; 86(24):10024-8.

21. Gross G, Gorochov G, Waks T, Eshhar Z. Generation of effector $\mathrm{T}$ cells expressing chimeric $\mathrm{T}$ cell receptor with antibody typespecificity. Transplant Proc. 1989; 21(1 Pt 1):127-30.

22. Wölfl M, Jungbluth AA, Garrido F, Cabrera T, Meyen-Southard S, Spitz R, et al. Expression of MHC class I, MHC class II, and cancer germline antigens in neuroblastoma. Cancer Immunol Immunother. 2005; 54(4):400-6.

23. Garcia-Lora A, Algarra I, Garrido F. MHC class I antigens, immune surveillance, and tumor immune escape. J Cell Physiol. 2003; 195(3):346-55.

24. Brudno JN, Somerville RP, Shi V, Rose JJ, Halverson DC, Fowler DH, et al. Allogeneic T Cells That Express an Anti-CD19 Chimeric Antigen Receptor Induce Remissions of B-Cell Malignancies That Progress After Allogeneic Hematopoietic StemCell Transplantation Without Causing Graft-Versus-Host Disease. J Clin Oncol. 2016; 34(10):1112-21.

25. Yu J, Freud AG, Caligiuri MA. Location and cellular stages of natural killer cell development. Trends Immunol. 2013; 34(12):573-82.

26. Lanier LL, Spits H, Phillips JH. The developmental relationship between NK cells and T cells. Immunol Today. 1992; 13(10):392-5.

27. Renoux VM, Zriwil A, Peitzsch C, Michaëlsson J, Friberg D, Soneji S, et al. Identification of a Human Natural Killer Cell Lineage-Restricted Progenitor in Fetal and Adult Tissues. Immunity. 2015; 43(2):394-407.

28. Dimopoulos MA, Oriol A, Nahi H, San-Miguel J, Bahlis NJ, Usmani SZ, et al. Daratumumab, Lenalidomide, and Dexamethasone for Multiple Myeloma. N Engl J Med. 2016; 375(14):1319-31.

29. Kimpo MS, Oh B, Lee S. The Role of Natural Killer Cells as a Platform for Immunotherapy in Pediatric Cancers. Curr Oncol Rep. 2019; 21(10):93.

30. Lee DA. Cellular therapy: Adoptive immunotherapy with expanded natural killer cells. Immunol Rev. 2019; 290(1):85-99.

31. Babor F, Manser AR, Fischer JC, Scherenschlich N, Enczmann $\mathrm{J}$, Chazara $\mathrm{O}$, et al. KIR ligand $\mathrm{C} 2$ is associated with increased susceptibility to childhood ALLand confers an elevated risk for late relapse. Blood. 2014; 124(14):2248-51.

32. Rueff J, Medinger M, Heim D, Passweg J, Stern M. Lymphocyte subset recovery and outcome after autologous hematopoietic stem cell transplantation for plasma cell myeloma. Biol Blood Marrow Transplant. 2014; 20(6):896-9.

33. Paczulla AM, Rothfelder K, Raffel S, Konantz M, Steinbacher J, Wang $\mathrm{H}$, et al. Absence of NKG2D ligands defines leukaemia stem cells and mediates their immune evasion. Nature. 2019; 572(7768):254-9.

34. Daneman R, Prat A. The blood-brain barrier. Cold Spring Harb Perspect Biol. 2015; 7(1):a020412. 


\section{Farhoud et al.}

35. Curtin SC, Minino AM, Anderson RN. Declines in Cancer Death Rates Among Children and Adolescents in the United States, 1999-2014. NCHS Data Brief. 2016; (257):1-8.

36. Siegel RL, Miller KD, Jemal A. Cancer statistics, 2018. CA Cancer J Clin. 2018; 68(1):7-30.

37. Finn OJ. Cancer immunology. N Engl J Med. 2008; 358(25):2704-15.

38. Ajina R, Zamalin D, Weiner LM. Functional genomics: paving the way for more successful cancer immunotherapy. Brief Funct Genomics. 2019; 18(2):86-98.
39. Yuen GJ, Demissie E, Pillai S. B lymphocytes and cancer: a love-hate relationship. Trends Cancer. 2016; 2(12):747-57.

40. Hamid O, Hoffner B, Gasal E, Hong J, Carvajal RD. Oncolytic immunotherapy: unlocking the potential of viruses to help target cancer. Cancer Immunol Immunother. 2017; 66(10):1249-64.

41. Yin J, Markert JM, Leavenworth JW. Modulation of the Intratumoral Immune Landscape by Oncolytic Herpes Simplex Virus Virotherapy. Front Oncol. 2017; 7:136. 